\title{
Management of obesity, insulin resistance and type 2 diabetes in children: consensus and controversy
}

This article was published in the following Dove Press journal: Diabetes, Metabolic Syndrome and Obesity:Targets and Therapy 10 December 2009

Number of times this article has been viewed

\author{
Amy Fleischman \\ Erinn T Rhodes \\ Division of Endocrinology, \\ Children's Hospital Boston, \\ Boston, MA, United States
}

Correspondence: Erinn T Rhodes Division of Endocrinology, Children's Hospital Boston, 333 Longwood Ave., 6th Floor, Boston, MA, 02II5, USA

$\mathrm{Tel}+\mathrm{I}$ 617-355-3209

Fax +| 617-730-0183

Email erinn.rhodes@childrens.harvard.edu

\begin{abstract}
Childhood obesity has become a national and international epidemic. The prevalence and incidence of type 2 diabetes in youth have been increasing, and type 2 diabetes is one of the most challenging complications of obesity in childhood. Comprehensive lifestyle interventions that include attention to dietary change, increased physical activity and behavior change appear to be required for the successful treatment of pediatric obesity. In particular, aspects of behavioral interventions that have been identified as contributing to effectiveness have included intensity, parent/family participation, addressing healthy dietary change, promoting physical activity, and involving behavioral management principles such as goal setting. A multidisciplinary team approach is required for successful management of type 2 diabetes in youth as well. As with many therapies in pediatrics, clinical trials and support for treatments of obesity and type 2 diabetes in youth lag behind adult data. Pediatric recommendations may be extrapolated from adult data and are often based on consensus guidelines. Type 2 diabetes in children is most commonly managed with lifestyle modification and medications, metformin and/or insulin, the only medications currently approved for use in children. However, many opportunities exist for ongoing research to clarify optimal management for obesity and type 2 diabetes in youth.
\end{abstract}

Keywords: children, obesity, type 2 diabetes, metformin, insulin, bariatric surgery

\section{Introduction}

Childhood obesity has become a national and international epidemic. This may be the greatest threat to the health of today's children and, if predictions hold true, may result in the first reduction in average lifespan for the current generation. ${ }^{1}$ The causes of the obesity epidemic are complex, and the treatments must therefore be comprehensive. In this review, we discuss management strategies for obesity, insulin resistance, and type 2 diabetes mellitus in childhood, and highlight some of the unresolved controversies in this therapeutic area.

\section{Obesity}

Childhood obesity is a worldwide epidemic. ${ }^{2}$ Given the global nature of the problem, the definition of obesity may also take on different meaning depending on the location. In the US, overweight in children is currently defined as a body mass index (BMI), weight in kilograms divided by the square of the height in meters, that is at or above the 85 th percentile for age and sex but below the 95 th percentile, and obesity is defined as a BMI that is at or above the 95 th percentile for age and sex. ${ }^{3}$ The reference data are the 2000 sex-specific BMI for age growth charts from the Centers for Disease Control and Prevention. ${ }^{4}$ However, in other parts of the world, different reference data or 
cut-offs may be used. To facilitate international comparisons, Cole et al have suggested age-specific BMI cut-offs based on international data that are linked to the adult cut-offs of $25 \mathrm{~kg} / \mathrm{m}^{2}$ for overweight and $30 \mathrm{~kg} / \mathrm{m}^{2}$ for obesity. ${ }^{5}$

In the US, a periodic population-based survey, the National Health and Nutrition Examination Survey (NHANES), has been used to monitor the prevalence of overweight and obesity among children. Data from NHANES surveys from 1976-1980 to 2003-2006 showed that the prevalence of obesity increased 2- to 3-fold. Among children aged 2 to 5 years, the prevalence increased from $5.0 \%$ to $12.4 \%$; among 6- to 11 -year-olds, prevalence increased from $6.5 \%$ to $17.0 \%$; and among 12 - to 19 -year-olds, prevalence increased from $5.0 \%$ to $17.6 \% .^{6,7}$ These worrisome trends also portend an increase in children at risk for complications including insulin resistance, type 2 diabetes, hypertension, dyslipidemia, and fatty liver ${ }^{3,8}$ as well as increased morbidity as adults. ${ }^{9,10}$

\section{Obesity-related comorbidities}

Multiple medical problems are associated with pediatric obesity including insulin resistance and type 2 diabetes mellitus. Other problems include dyslipidemia and hypertension as well as polycystic ovary syndrome, steatohepatitis, obstructive sleep apnea, orthopedic complications, and mental illness, especially depression. In this review, we will focus on insulin resistance and type 2 diabetes. Although not discussed in detail in this review, recent consensus statements on screening, therapeutics and follow up in children with altered lipid parameters ${ }^{11}$ and hypertension ${ }^{12}$ are available. Evaluation of children for obesity must include consideration and evaluation of these associated medical problems.

\section{Insulin resistance and the metabolic syndrome}

Metabolic syndrome, also termed the dysmetabolic syndrome, syndrome $\mathrm{X}$ or the insulin resistance syndrome, is a group of related risk factors associated with obesity and type 2 diabetes, which is predictive of cardiovascular disease in adults. ${ }^{13-16}$ The elements include measures of adiposity, lipids, glucose and blood pressure. There are several definitions of this syndrome in adulthood including those from the World Health Organization, ${ }^{13}$ the National Cholesterol Education Program, ${ }^{14}$ and the International Diabetes Federation. ${ }^{15}$ More recently, the American Heart Association (AHA) and the National Heart, Lung and Blood Institute (NHLBI) modified the glucose parameters used in their definition of the metabolic syndrome to be more inclusive. ${ }^{16}$ There is a lack of consensus in the pediatric literature about the elements, the pediatric cut-offs and the clinical relevance of this syndrome in children. Some have applied the adult cut-offs in the pediatric age range. ${ }^{17}$ However, most pediatric investigators have endorsed pediatric specific cut-offs such as those proposed by de Ferranti and others, ${ }^{18}$ based on the NHANES data. These include: waist circumference $\geq 75$ th percentile for age and sex; systolic or diastolic blood pressure for age, sex and height $\geq 90$ th percentile; triglycerides $\geq 100 \mathrm{mg} / \mathrm{dL}$; high-density lipoprotein (HDL) for boys 15 to 19 years old $<45 \mathrm{mg} / \mathrm{dL}$; and HDL for all others $<50 \mathrm{mg} / \mathrm{dL}$; and fasting glucose $\geq 110 \mathrm{mg} / \mathrm{dL}$. Several other similar criteria for the pediatric population have been proposed. ${ }^{19-21}$ However, regardless of the specific definition, it remains to be determined to what extent these metabolic abnormalities, as a group, may represent a state of increased risk for progression to type 2 diabetes and cardiovascular disease in children. ${ }^{22,23}$ Therefore, this review focuses on obesity and insulin resistance as well as type 2 diabetes mellitus. It is difficult to focus on a single metabolic complication as the lack of consensus definition leads to variable research endpoints. However, there is consensus that one of the key approaches to managing these metabolic abnormalities is to promote reduction in BMI using therapies for obesity as outlined below. Identifying the risk factors associated with the metabolic syndrome can guide the intensity and breadth of the interventions prescribed.

\section{Type 2 diabetes}

Type 2 diabetes mellitus refers to a nonautoimmune form of diabetes characterized by insulin resistance and relative insulin deficiency. Almost unheard of in children only a few decades ago, the epidemic of childhood obesity has contributed to a progressive increase in the incidence and prevalence of type 2 diabetes in the US and around the world. ${ }^{24-31}$ In absolute terms, the overall number of children with type 2 diabetes remains relatively small in many parts of the world. For example, a recent study from the UK reported a prevalence of type 2 diabetes in children less than 17 years of age of 0.21 per 100,000 or approximately 1 per $500,000 .^{31}$ However, recent estimates of the prevalence and incidence of type 2 diabetes in children in the US are several fold higher than those in Europe. ${ }^{32}$ In the US, the SEARCH for Diabetes in Youth Study, which began in 2000, has provided the most comprehensive estimates of the prevalence and incidence of type 2 diabetes among youth less than 20 years of age in the US. The prevalence of type 2 diabetes among 10- to 19-yearold youth ranged from $0.18 / 1000$ (approximately 1 in 5600) 
for non-Hispanic White youth to 1.45/1000 (approximately 1 in 700) for Navajo youth, and the incidence ranged from 3.7/100,000/year for non-Hispanic White youth to 27.7/100,000/year for Navajo youth. ${ }^{32,33}$ Prevalence and incidence of type 2 diabetes for Black, Hispanic, Asian, and Pacific Islander US youth are intermediate. ${ }^{34-36}$ The incidence of type 2 diabetes is also increasing in the UK, and children of ethnic minorities are also at higher risk with Blacks and those of South-Asian origin (in England) having an incidence of 3.9 and 1.25/100,000/year, respectively, compared with $0.35 / 100,000 /$ year in White children. ${ }^{29}$ In Tokyo, the incidence of type 2 diabetes in children has also been increasing with a rate of $2.76 / 100,000 /$ year since 1981 compared to $1.73 / 100,000 /$ year before $1980 .^{26}$ Ongoing research will be needed to monitor these patterns.

\section{Management of obesity and insulin resistance Lifestyle modification}

Several recent guidelines for the management of pediatric obesity $^{3,37}$ have stressed that comprehensive lifestyle interventions, that include attention to dietary change, increased physical activity and behavior modification, are required for the successful treatment of pediatric obesity. Understanding the individual contribution of each of these therapies to the overall success of the intervention has been the focus of ongoing research.

With regard to dietary interventions, a recent Cochrane review of interventions for treatment of obesity in children, identified only 6 studies ( 4 in children less than 12 years old and 2 in children 12 years and older) that met the review criteria. ${ }^{38}$ Criteria for inclusion in the review for lifestyle interventions included randomized controlled trials that were specifically designed to evaluate the impact of obesity treatment in children or adolescents with at least 6 months' duration. ${ }^{38}$ Other systematic reviews of interventions for pediatric obesity have similarly demonstrated few high-quality studies addressing this issue. ${ }^{39,40}$ Given the emphasis on a multidisciplinary approach to pediatric weight management, few studies have been designed to specifically evaluate the impact of the dietary component of the intervention. Collins et $\mathrm{al}^{40}$ reported a meta-analysis of 8 studies that included a dietary component and an adequate control group that was either no intervention, waiting list or usual care. They found that studies including a dietary component effectively achieved relative weight loss among overweight/obese children and adolescents. However, further analysis of a subset with longer follow up demonstrated a loss of some of these benefits over time. Maintenance support following an intensive intervention may be required for longterm success. ${ }^{41}$

Recent guidelines on management of pediatric obesity have concluded that evidence is insufficient to recommend one specific diet over another. ${ }^{3,37}$ One comparison of interest has focused on the benefits of a low fat vs a low glycemic index diet. Other studies have also evaluated a proteinsparing modified diet, high-protein diet, or energy restricted interventions. The Cochrane review commented on one adolescent study by Ebbeling et $\mathrm{al}^{42}$ which demonstrated that, after 12 months, subjects on an ad libitum low glycemic load diet lost significantly more weight than those on an energy restricted low fat diet (a difference of 2 BMI units, $n=16$, $P<0.05$ ). Amongst the studies included in the meta-analysis by Collins et al, Saelens et $\mathrm{al}^{43}$ evaluated a 4 -month behavioral weight control program for overweight adolescents initiated in a primary care setting compared to a single session of physician weight counseling. The dietary recommendations within the intervention were aimed at fat and calorie reduction. Adolescents in the treatment group were found to have modest reduction in BMI z-score whereas those in the control had an increase in BMI z-score. Further, $40 \%$ of the treatment group achieved reduction in BMI z-score vs $10.5 \%$ in the control group $(P<0.04)$. Further studies comparing dietary interventions while maintaining other aspects of the intervention constant, such as behavioral support and physical activity recommendations, are needed. At present, general dietary guidelines include avoiding consumption of calorie-dense, nutrient-poor foods; reducing intake of dietary saturated fat and increasing intake of dietary fiber, fruits and vegetables. ${ }^{37}$

Exercise has been recognized as an essential component of treatment for obesity, insulin resistance and type 2 diabetes in children. The Centers for Disease Control and Prevention recommend that children perform 60 minutes of exercise daily to promote health and reduce the risk of obesity and its complications. ${ }^{44}$ The type, duration and schedule of exercise recommended for children remain an area of controversy. Furthermore, as suggested in the Cochrane review, ${ }^{38}$ the comparability of different exercise interventions is often unclear, and therefore the efficacy of exercise as a treatment for pediatric obesity remains difficult to formally evaluate in children.

A systematic review of the impact of resistance training on metabolic fitness in children was conducted in 2008 and found a total of 12 relevant studies. ${ }^{45}$ The majority of reported 
studies were relatively short, between 6 and 10 weeks in duration, and with 1 to 5 days of supervised activity per week. In most studies, metabolic outcomes were evaluated by fasting lipid panels, fasting insulin and glucose levels and were unchanged by the intervention. In contrast, there is ample evidence that resistance training in adults can reduce insulin resistance, and reduce the incidence of type 2 diabetes in high risk adults. ${ }^{46}$

More data are available on the specific impact of aerobic exercise on overweight/obese children. In a study of 19 overweight and obese adolescent girls, Nassis et al showed that aerobic training for 12 weeks was able to reduce the insulin area under the curve based on oral glucose tolerance testing by $23.3 \%$ without changes in body weight or percent body fat. ${ }^{47}$ Similarly, a school-based aerobic fitness intervention of 50 obese middle school age children demonstrated a loss of body fat, increase in cardiovascular fitness, and improve- ment in fasting insulin levels in the treated compared to control subjects over 9 months. ${ }^{48}$ Finally, Bell et al showed improvement in insulin sensitivity by hyperinsulinemic euglycemic clamp after an eight week mixed aerobic and resistance training intervention in a small study of obese, insulin-resistant children without changes in body weight or body composition. ${ }^{49}$ However, the benefit of exercise alone on weight reduction in children remains in question. The recent Cochrane analysis suggested that family-based lifestyle interventions with a behavioral program targeting physical activity as well as dietary change can be successful in treatment of pediatric obesity. ${ }^{38}$ The results of interventions specifically targeting physical activity on short- and longterm weight loss were variable. ${ }^{38}$ However, the benefit of regular exercise on some metabolic parameters, including insulin resistance, was clear even in the setting of lack of weight changes (Table 1).

Table I Studies of interventions influencing insulin resistance in children: exercise and metformin

\begin{tabular}{|c|c|c|c|c|c|}
\hline References & Size and subjects & Study design & Intervention & Duration & Primary outcome \\
\hline \multicolumn{6}{|l|}{$\begin{array}{l}\text { Exercise } \\
\text { interventions }\end{array}$} \\
\hline Bell et $\mathrm{al}^{49}$ & $\begin{array}{l}\text { I4 obese } \\
\text { (BMI }>95 \text { th \%), } \\
9 \text { to } 16 \text { years old }\end{array}$ & Open, single arm & $\begin{array}{l}\text { Mixed aerobic } \\
\text { and resistance } \\
\text { training, 3, I-hour } \\
\text { sessions per week, } \\
\text { hyperinsulinemic } \\
\text { euglycemic clamp }\end{array}$ & 8 weeks & $\begin{array}{l}\text { Improved insulin sensitivity } \\
\text { by clamp }\end{array}$ \\
\hline Nassis et $\mathrm{al}^{47}$ & $\begin{array}{l}19 \text { overweight girls } \\
\text { (BMI }>85 \text { th \%), } \\
9 \text { to } 15 \text { years old }\end{array}$ & Open, single arm & $\begin{array}{l}\text { Aerobic training, } \\
40 \text { minutes, } 3 \text { days } \\
\text { per week, OGTT }\end{array}$ & 12 weeks & $\begin{array}{l}\text { Reduced insulin AUC, } \\
\text { no change in fasting insulin } \\
\text { and HOMA-IR }\end{array}$ \\
\hline Carrel et $\mathrm{al}^{48}$ & $\begin{array}{l}50 \text { obese } \\
(\text { BMI }>95 \text { th \%) } \\
\text { middle school } \\
\text { students }\end{array}$ & Randomized, controlled & $\begin{array}{l}\text { School-based small } \\
\text { fitness classes, } \\
\text { fasting laboratory } \\
\text { studies }\end{array}$ & 9 months & Reduced fasting insulin \\
\hline \multicolumn{6}{|l|}{ Metformin } \\
\hline Freemark et al ${ }^{57}$ & $\begin{array}{l}29 \text { obese } \\
\left(\text { BMI }>30 \mathrm{~kg} / \mathrm{m}^{2}\right), \\
\text { elevated fasting } \\
\text { insulin and family } \\
\text { history of type } 2 \\
\text { diabetes mellitus, } \\
12-19 \text { years old }\end{array}$ & $\begin{array}{l}\text { Double-blind, randomized, } \\
\text { controlled }\end{array}$ & $\begin{array}{l}\text { Metformin } 500 \mathrm{mg} \\
\text { or placebo twice } \\
\text { daily, FSIVGTT }\end{array}$ & 6 months & $\begin{array}{l}\text { Improved fasting glucose } \\
\text { and insulin levels, } \\
\text { no significant improvement } \\
\text { in insulin sensitivity } \\
\text { parameters by minimal } \\
\text { model analysis }\end{array}$ \\
\hline Atabek et $\mathrm{al}^{60}$ & $\begin{array}{l}\text { I } 20 \text { obese } \\
\text { (BMI }>95 \text { th \%), } \\
9-17 \text { years old }\end{array}$ & $\begin{array}{l}\text { Double-blind, randomized, } \\
3: 1, \text { controlled }\end{array}$ & $\begin{array}{l}\text { Metformin } 500 \mathrm{mg} \\
\text { or placebo twice } \\
\text { daily, OGTT }\end{array}$ & 6 months & $\begin{array}{l}\text { Improved fasting insulin, } \\
\text { I20-minute insulin, } \\
\text { HOMA-IR }\end{array}$ \\
\hline Srinivasan et a ${ }^{59}$ & $\begin{array}{l}22 \text { obese and } \\
\text { insulin resistant, } \\
9-18 \text { years old }\end{array}$ & $\begin{array}{l}\text { Double-blind, randomized } \\
\text { to metformin or placebo } \\
\text { for cross over, controlled }\end{array}$ & $\begin{array}{l}\text { Metformin I g twice } \\
\text { daily, FSIVGTT }\end{array}$ & $\begin{array}{l}12 \text { months } \\
\text { ( } 6 \text { months each } \\
\text { intervention) }\end{array}$ & $\begin{array}{l}\text { Improved fasting glucose } \\
\text { and insulin, no significant } \\
\text { improvement in insulin } \\
\text { sensitivity parameters by } \\
\text { minimal model analysis }\end{array}$ \\
\hline
\end{tabular}

Abbreviations: AUC, area under the curve; FSIVGTT, frequently sampled intravenous glucose tolerance test; HOMA-IR, homeostasis model assessment-insulin resistance; OGTT, oral glucose tolerance test. 
A variety of behavioral approaches to address pediatric obesity have been proposed..$^{38,39}$ The heterogeneity of the interventions has made identifying the importance of specific aspects or approaches difficult in systematic reviews. ${ }^{39}$ However, aspects of behavioral interventions that have been identified as contributing to effectiveness have included intensity, parent/family participation, addressing healthy dietary change, promoting physical activity, and involving behavioral management principles such as goal setting. ${ }^{39}$ However, in clinical practice, high rates of attrition in multidisciplinary and family-based treatment programs for pediatric obesity have been documented with estimates as high as $34 \%$ to $64 \%$ of families..$^{50,51}$ Additional research is still needed to understand how to make effective interventions more generalizable. Behavioral interventions are an essential component of a comprehensive lifestyle modification program and the intervention itself must be flexible enough to adjust to individual and family needs.

\section{Medical intervention}

Pharmacologic therapies for the treatment of obesity remain an area of intense scientific interest. Although there are now several categories of approved medical therapies in adults, there are limited studies in children and adolescents addressing their safety and efficacy. A recent meta-analysis performed for The Endocrine Society ${ }^{52}$ determined that there were 17 pediatric trials of pharmacologic agents for treatment of pediatric obesity. These included trials of sibutramine, orlistat and metformin as well as a smaller number of trials evaluating sympathomimetics, dehydroepiandrosterone, and fiber supplements. This meta-analysis included fully published trials of any duration through February 2006. A more recent meta-analysis of metformin for treatment of pediatric obesity included trials of at least 6 months duration through December 2008. ${ }^{53}$ Discussion of metformin, sibutramine and orlistat are presented separately below. Each of these medications may have a role in selected high risk populations of obese adolescents in conjunction with intensive lifestyle modification (Table 2).

\section{Metformin}

Metformin is an oral hypoglycemic agent that is approved in the pediatric population (age 10 years and older) for the treatment of type 2 diabetes. It is a biguanide, and its primary action is to reduce hepatic glucose production and to secondarily improve peripheral insulin sensitivity. It is not currently approved for use in obesity or insulin resistance in adolescents, and its use for these indications has been

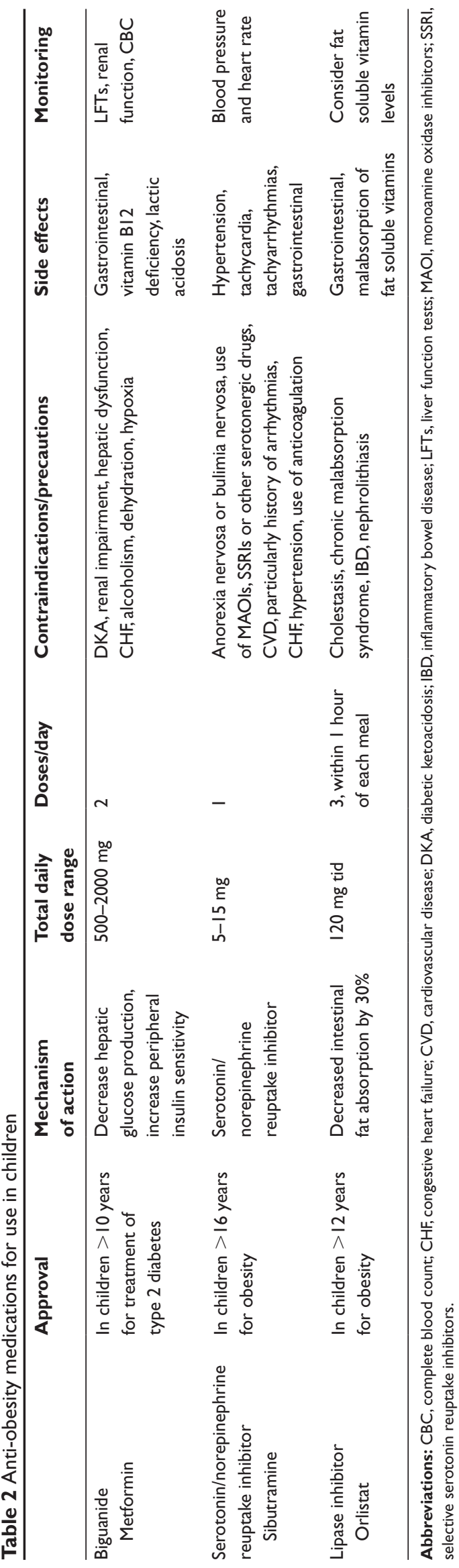


an area of debate. Interest in metformin for obesity arises from its success in adult studies, most notably the Diabetes Prevention Program, ${ }^{54}$ which demonstrated a 31\% reduction in risk of type 2 diabetes among high risk adults with metformin therapy. Use of metformin to treat obesity-related comorbidities associated with insulin resistance, such as polycystic ovarian syndrome (PCOS) ${ }^{55}$ and nonalcoholic steatohepatitis, ${ }^{56}$ has also been under investigation.

The two small meta-analyses of randomized trials of metformin therapy in pediatrics used overlapping but not equivalent sets of studies and arrived at differing conclusions. The earlier meta-analysis by McGovern et al of three trials ${ }^{57-59}$ of metformin monotherapy therapy in obese hyperinsulinemic adolescents showed no significant change in BMI at 6 months (SMD $-0.17,95 \% \mathrm{CI}-0.62,0.28) .{ }^{52}$ More recently, Park et al conducted a meta-analysis of the 320 individuals in 5 trials $\mathrm{s}^{57,59-62}$ of at least 6 months' duration, using 1000 to $2000 \mathrm{mg}$ of metformin daily and concluded that metformin reduced BMI by $1.42 \mathrm{~kg} / \mathrm{m}^{2}$ (95\% CI 0.83 , 2.02) and reduced insulin resistance assessed by HOMA-IR while showing minimal changes in fasting insulin, glucose, cholesterol levels and blood pressure. ${ }^{53}$

Studies included in both meta-analyses included those by Freemark et $\mathrm{l}^{57}$ and Srinivasan et al. ${ }^{59}$ Both studies had primary endpoints of weight and insulin resistance. Freemark et al ${ }^{57}$ evaluated 29 obese adolescents with fasting hyperinsulinemia and a family history of type 2 diabetes in a 6-month, doubleblind, placebo-controlled trial. Treated subjects received metformin $500 \mathrm{mg}$ twice daily and showed a reduction in BMI $\left(-0.5 \mathrm{~kg} / \mathrm{m}^{2}\right)$ and BMI SDS $(-0.12)$ and improved insulin sensitivity. Srinivasan et al ${ }^{59}$ studied 28 children, ages 9 to 18 years, who received metformin $1000 \mathrm{mg}$ twice daily or placebo for 6 months, with a 2 week wash out between each intervention. They found metformin had a greater treatment effect over placebo for weight $(-4.35 \mathrm{~kg}, P=0.02)$, body mass index $\left(-1.26 \mathrm{~kg} / \mathrm{m}^{2}, P=0.002\right)$, waist circumference $(-2.8 \mathrm{~cm}$, $P=0.003)$, abdominal adipose tissue $\left(-52.5 \mathrm{~cm}^{2}, P=0.002\right)$, and fasting insulin $(-2.2 \mathrm{mU} / \mathrm{L}, P=0.011)$. In another small 8 week trial of metformin $850 \mathrm{mg}$ twice daily compared to placebo, Kay et $\mathrm{al}^{58}$ showed a small but significant reduction in BMI, as well as lipid parameters among 24 hyperinsulinemic obese adolescents. Other more recent studies have also demonstrated improvements in both insulin sensitivity and reduction in BMI among metformin-treated obese children and adolescents. ${ }^{60,63} \mathrm{One}^{60}$ used insulin resistance as a primary endpoint. Thus, small studies demonstrate improvements in insulin sensitivity and other metabolic factors, with small reductions in BMI or weight and, when pooled, a subset showed significant reductions in BMI in one meta-analysis. The studies demonstrated limited safety concerns, with the most common side effect being gastrointestinal with resolution with dose reduction. ${ }^{57,59}$ The three studies with insulin resistance as a primary outcome are outlined in more detail in Table 1.

Metformin has also been shown to reduce visceral fat, insulin resistance and hyperandrogenism in a population of girls from Spain, who are both of low birth weight and develop premature adrenarche. The use in these girls in prepuberty appears to modify some of the pathologic changes in glucose metabolism and body composition that accompany puberty. ${ }^{64-66}$ Although extremely encouraging, the generalizability of these findings to other populations remains an area of investigation.

\section{Sibutramine}

Sibutramine is a serotonin and norepinephrine reuptake inhibitor. Sibutramine is currently approved for use in the United States in adolescents over the age of 16 years. Three randomized placebo-controlled trials of sibutramine in adolescents were pooled in a meta-analysis ${ }^{52}$ and demonstrated a significant loss of BMI of $2.4 \mathrm{~kg} / \mathrm{m}^{2}(95 \% \mathrm{CI}$ $1.8,3.1)$ after 6 months. The first study, by Berkowitz et al, ${ }^{67}$ enrolled 82 children who were randomized to sibutramine or placebo for 6 months followed by a 6-month, open-label sibutramine extension phase. The medication therapy was used in combination with a behavioral protocol including group meetings for participants and families, recommendations for a low calorie diet and exercise. The sibutramine group had a significantly greater reduction in BMI (8.5\% vs $4.0 \%$ ) compared to the placebo-treated group at 6 months. There was evidence of increase in blood pressure and heart rate in the children treated with sibutramine. In fact, 19 of 43 children had the medication reduced (from $15 \mathrm{mg}$ to 10 or $5 \mathrm{mg}$ ) or discontinued due to alterations in blood pressure or heart rate during the trial. Godoy-Matos et al ${ }^{68}$ conducted a randomized, double-blind, placebo-controlled study with 60 adolescents treated for 6 months with sibutramine (10 mg daily) as well as a hypocaloric diet and exercise recommendations given at the initiation of the study. This study demonstrated a significantly greater reduction in BMI in the sibutramine group (3.6 vs $\left.0.9 \mathrm{~kg} / \mathrm{m}^{2}\right)$. The difference in the change in weight and BMI became significant at 4 weeks and remained so for the duration of the 6-month intervention. Almost half (46.6\%) of the adolescents in the sibutramine group reduced their weight by $10 \%$. Participants had echocardiograms at baseline and completion of the study without significant findings. There were no noted changes 
in glucose or insulin values. However, there were favorable changes in lipid parameters in this study. Importantly, this study did not include an intensive behavioral management plan and may therefore be more representative of a standard clinical scenario. In addition, although smaller, this study did not demonstrate significant changes in blood pressure or heart rate. A small study ${ }^{69}$ evaluated BMI and body composition by underwater weighing and dual X-ray absorptiometry. The 24 subjects received sibutramine $(10 \mathrm{mg})$ or placebo plus an energy restricted diet and exercise plan for 12 weeks. The study found no differences in BMI or body composition between the two groups at study completion. Therefore, the absolute effect size of the addition of sibutramine to a standard or intensive weight loss program remains an area of controversy. The Sibutramine Adolescent Study Group has performed the largest studies addressing the efficacy and safety of this medication. Published in $2006,{ }^{70}$ this multicenter trial enrolled 498 children, ages 12 to 16 years, for a 12-month trial of sibutramine (10-15 mg) or placebo, plus a behavior therapy program including lifestyle modification. Completion rates were $72 \%$ in the sibutramine group and $62 \%$ in the placebo group. The sibutramine group had a significant reduction in BMI $\left(-2.9 \mathrm{vs}-0.3 \mathrm{~kg} / \mathrm{m}^{2}\right)$. Almost half of the participants $(45.6 \%)$ had a $10 \%$ reduction in BMI in the sibutramine group compared to $6.3 \%$ in the placebo group. In addition, lipid parameters and insulin levels improved in the medication group. Therefore, this large study supported the efficacy of this medication over behavioral therapy alone, but the treatment effect of the entire intervention remained small. The same group published a safety evaluation addressing the cardiovascular effects of the treatment in this group. ${ }^{71}$ In the medication-treated group, $13 \%$ experienced tachycardia compared to $6 \%$ in the placebo-treated group. However, the study found no statistically significant differences in blood pressure between groups, and both groups showed small reductions in blood pressure parameters in association with weight loss. However, children with hypertension and tachycardia were excluded from the study. Of note, the FDA recently added additional warnings to the labeling of sibutramine to include the potential for serotonin syndrome, especially in association with the use of selective serotonin reuptake inhibitors (SSRIs), monoamine oxidase inhibitors (MAOIs), serotonergic drugs such as triptans or some antipsychotics, but also when used alone.

\section{Orlistat}

Orlistat, a gastrointestinal tract lipase inhibitor, can decrease the intestinal fat absorption by up to $30 \%$. This has been the only approved therapy for adolescent obesity (ages 12-16 years) since December of 2003. Three randomized clinical trials of orlistat therapy pooled in a meta-analysis ${ }^{52}$ demonstrated a significant reduction in BMI of $0.7 \mathrm{~kg} / \mathrm{m}^{2}(95 \%$ CI $0.3,1.2)$. In 2002, a small open-label study of 20 participants treated for 6 months in association with a lifestyle modification program was completed. ${ }^{72,73}$ Children with morbid obesity (mean BMI of $44.1 \mathrm{~kg} / \mathrm{m}^{2}$ ) plus a comorbidity were enrolled. The 3-month ${ }^{72}$ and 6 -month ${ }^{73}$ data revealed a significant reduction in BMI of 1.9 and $2 \mathrm{~kg} / \mathrm{m}^{2}$, respectively, as well as improvements in lipids, insulin and glucose levels. Norgren et $\mathrm{al}^{74}$ and Ozkan et $\mathrm{al}^{75}$ performed small clinical trials of 4 to 15 months' duration and demonstrated significant weight reduction of similar magnitude but also called attention to the gastrointestinal side effects of orlistat in children and adolescents. One double-blind, placebo-controlled, 6-month clinical trial in 40 participants, performed by Maahs et al ${ }^{76}$ demonstrated no significant difference in BMI between the medication and placebo groups.

By far the largest trial has been a large multicenter, randomized, double-blind study of 539 adolescents published in $2005 .{ }^{77}$ Enrollment criteria included age 12 to 16 years and $\mathrm{BMI} \geq 2$ units or higher than the 95 th percentile for age and sex. Participants were excluded for a BMI of greater than $44 \mathrm{~kg} / \mathrm{m}^{2}$, recent weight loss, diabetes or obesity-related medications or syndromes. The study medication, orlistat $120 \mathrm{mg} 3$ times daily or placebo, was given for 52 weeks, in addition to a hypocaloric diet, behavioral modification, and exercise counseling. Completion rates were $65 \%$ and $64 \%$ in the medication and placebo groups respectively. At completion of the study, the participants in the orlistattreated group had decreased the BMI from baseline by $0.55 \mathrm{~kg} / \mathrm{m}^{2}$, while the placebo-treated group had increased by $0.31 \mathrm{~kg} / \mathrm{m}^{2}$. Although these values were significantly different, the mean change in kilograms in the treated group was essentially zero at the completion of the study. However, the orlistat-treated participants did regain less weight than the placebo-treated participants. Furthermore, the orlistattreated group also had a significantly greater decrease in waist circumference and body fat compared to placebo, although there were no significant differences in lipid, glucose or insulin levels. Over $50 \%$ of the orlistat-treated participants had gastrointestinal side effects, although only $2 \%$ discontinued therapy. Concern about malabsorption is heightened in adolescents, who require sufficient vitamins for completion of growth, development and bone accrual. Orlistat directly reduces the absorption of fat soluble vitamins. Several studies utilized a daily multivitamin, ${ }^{77}$ 
or specific supplementation of fat soluble vitamins. ${ }^{73}$ Even with supplementation, as recommended by the FDA, some participants demonstrated reductions in fat soluble vitamins, particularly vitamin $\mathrm{D} .{ }^{78}$ Overall, orlistat shows some efficacy in reducing BMI in obese adolescents. Gastrointestinal side effects are common, and fat soluble vitamin levels should be supplemented and monitored during therapy.

Taken together, these studies suggest that metformin may have efficacy in targeting insulin resistance in adolescents and may contribute to short-term weight loss. The longterm benefit remains unclear. There are also some data to support the efficacy of both sibutramine and orlistat for BMI reduction in selected high risk adolescents in association with a comprehensive weight loss program. As suggested by recent expert consensus guidelines, ${ }^{3,37}$ pharmacologic therapy should only be prescribed by clinicians experienced in the use of these medications and the associated monitoring that is required. Further, these treatments should be considered only when aggressive lifestyle intervention alone has been unsuccessful in weight management and in the prevention or resolution of obesity-related comorbidities.

\section{Bariatric surgery}

Bariatric surgery has been shown to improve both obesity and obesity-related comorbidities when utilized in the adult population to treat morbid obesity with complications. ${ }^{79}$ The data in children are more limited. An ongoing effort by the National Institute of Diabetes and Digestive and Kidney Diseases (NIDDK), National Institutes of Health, the Teen-Longitudinal Assessment of Bariatric Surgery, will serve as the first study to investigate safety and efficacy in a large cohort of adolescents undergoing bariatric surgery at multiple centers. To date, published reports are limited in number of participants and duration of follow up. However, a meta-analysis of the current data ${ }^{80}$ indicates a $36 \%$ reduction in BMI by 5 years postoperatively. These are similar to the data reported in the adult population. Furthermore, recent studies suggest that surgical weight loss may cause improvements or remittance of diabetes mellitus, as has been seen in adult studies. ${ }^{81}$ Although these studies are few, the mechanism in adults appears to be the surgical process and not the degree of weight loss suggesting similar improvements may occur in adolescents with type 2 diabetes. Importantly, preliminary adolescent studies also demonstrate that quality of life and depression measures improve in the year following surgical weight loss. ${ }^{82}$ Complication rates in adolescents are $\operatorname{similar}^{83}$ or lower ${ }^{84}$ compared to those in adults although adolescent surgeries of this type make up a small portion of the surgeries conducted annually in the US $(<1 \%$ in 2003).

The current options for bariatric surgery include adjustable banding, gastric bypass with Roux-en-Y, gastric sleeve and biliopancreatic bypass with duodenal switch. The standard of care for adolescents is the gastric bypass surgery, as the adjustable band is only FDA approved for individuals over the age of 18 years. However, a number of centers are able to perform the adjustable banding and, in one survey about procedure preference, ${ }^{85}$ a majority chose the gastric band procedure for adolescents due to the noninvasive nature of the surgery and the ability to noninvasively adjust the band. Gastric banding does reduce the risks of vitamin deficiencies. However, the reoperation rates, including band removal, are high $(8 \%-10 \%),{ }^{86,87}$ and therefore the safety of both surgeries should be considered. Other procedures are currently in the investigational stage for adolescents. The efficacy and safety of each procedure in this population will be better understood after the accumulation of additional data. Thus, it remains premature to recommend one method for use in the adolescent population.

There are several important considerations regarding the use of bariatric surgery in adolescents. Age and ongoing linear growth must be considered as should the child's maturity and psychological appropriateness for a procedure that will require lifelong change in dietary habits. , $^{3,37}$ In addition, candidates for surgical procedures must be evaluated in the context of the family. Adolescents are particularly at risk for nutrient deficiencies, including iron, vitamin D and calcium, ${ }^{88,89}$ and weight loss surgery can result in worsening of these deficiencies. ${ }^{90}$ As adolescence is an essential time period for bone accrual, these deficiencies should be avoided and thus surgical candidates must agree to closely comply with nutritional guidelines and supplementation. All participants must have a thorough medical and psychological evaluation prior to the procedure to evaluate the preparedness of the patient and family. 3,37,91 Contraindications include lack of supportive home structure, substance abuse, pregnancy or significant risk of pregnancy, or medical syndrome underlying the obesity that could be further evaluated. Psychological illness, such as depression, should be evaluated and appropriately treated prior to the procedure. Due to the frequent co-occurrence of mental illness in obesity, comprehensive evaluation must be performed with each individual to determine capacity for compliance with the pre-operative, operative and post operative protocols. In addition, the determination of adequate 
treatment for mental illness should be assessed by an appropriately trained mental health provider familiar with the procedure and necessary compliance.

Consensus guidelines for use of bariatric surgery in obese adolescents are available..$^{3,37,91}$ Recommendations were developed after expert reviewers performed systematic searches of the literature with evidence grading scales to support recommendations. These panels suggest that adolescents should be considered for surgical therapy only after failure of an age appropriate, multidisciplinary weight management treatment of at least 6 months in duration. The details of such a program, as addressed in this review, remain an area of debate in the field. Appropriate patients would have morbid obesity, BMI of greater than or equal to $40 \mathrm{~kg} / \mathrm{m}^{2}$ with other comorbidities, or over $35 \mathrm{~kg} / \mathrm{m}^{2}$ plus serious comorbidities such as type 2 diabetes mellitus, severe steatohepatitis, severe sleep apnea, or pseudotumor cerebri. ${ }^{91}$ The use of numerical cut-offs in lieu of percentiles in adolescents was chosen to provide a more conservative recommendation. ${ }^{91}$ The BMI cut-offs recommended by the Endocrine Society ${ }^{37}$ and recent Expert Committee Recommendations endorsed by the American Academy of Pediatrics $^{3}$ are slightly more conservative recommending consideration of bariatric surgery when the BMI is greater than or equal to $50 \mathrm{~kg} / \mathrm{m}^{2}$ or $40 \mathrm{~kg} / \mathrm{m}^{2}$ with other comorbidities. In addition, the guidelines recommend that patients should be post pubertal or in late puberty and have attained near final adult stature. Patients and families should demonstrate the ability to comprehend the procedure and its risks; provide informed consent and/or assent; and be capable of adhering to the medical and nutritional postoperative plan. Consistent with recent guidelines, high risk adolescents with severe obesity and medical comorbidities meeting these criteria, whose health deteriorates despite aggressive lifestyle intervention, may be considered for evaluation of bariatric surgery on an individualized basis with experts in this surgical specialty.

\section{Identification and diagnosis of type 2 diabetes mellitus}

There remains debate about the optimal strategy and frequency for testing for type 2 diabetes in youth at risk. ${ }^{92,93}$ Currently, the American Diabetes Association ${ }^{92}$ recommends testing children who are overweight (defined as having a BMI $>85$ th percentile for age and sex, weight for height $>85$ th percentile, or weight $>120 \%$ of ideal for height) and have any 2 additional risk factors including family history of type 2 diabetes in a first or second degree relative; race/ethnicity of Native American, African-American, Latino, Asian American or Pacific Islander; signs of insulin resistance or conditions associated with insulin resistance such as acanthosis nigricans, hypertension, dyslipidemia, PCOS, or small for gestational age birth weight; and maternal history of diabetes or gestational diabetes during the child's gestation. Testing is recommended to begin at age 10 years or at puberty if puberty occurs at a younger age and should be repeated every 3 years. Fasting plasma glucose is the preferred test. Three criteria can be used to establish the diagnosis of diabetes mellitus. ${ }^{92}$ These are (1) symptoms of diabetes such as polyuria, polydipsia or unexplained weight loss plus casual (random) plasma glucose concentration $\geq 200 \mathrm{mg} / \mathrm{dL}$ or (2) fasting plasma glucose $\geq 126 \mathrm{mg} / \mathrm{dL}$ or (3) plasma glucose $\geq 200 \mathrm{mg} / \mathrm{dL}$ at 2 hours during a standard oral glucose tolerance test. In the absence of unequivocal symptoms of hyperglycemia, confirmation on a second day is also recommended. ${ }^{92}$ However, new recommendations from an International Expert Committee with representation from the American Diabetes Association, the European Association for the Study of Diabetes and International Diabetes Federation have proposed the use of $\mathrm{HbA}_{1 \mathrm{c}}$ for diabetes diagnosis with a level at or above $6.5 \%$ considered diagnostic of diabetes. ${ }^{94}$ The $\mathrm{HbA}_{1 \mathrm{c}}$ should be repeated for confirmation unless there are symptoms of diabetes and a random plasma glucose level $>200 \mathrm{mg} / \mathrm{dL} .^{94}$

Children with type 2 diabetes are typically overweight, have evidence of insulin resistance, and frequently have a family history of type 2 diabetes in a first- or second-degree relative. ${ }^{95}$ Children belonging to certain racial/ethnic groups, including Blacks and Hispanics, are also at higher risk. ${ }^{95}$ However, the increasing prevalence of obesity in children ${ }^{7}$ has made differentiating between type 1 and type 2 diabetes difficult at times. ${ }^{96}$ Children with phenotypic characteristics of type 2 diabetes may also have pancreatic autoimmunity, ${ }^{97,98}$ and an increasing number of children with diabetes that require exogenous insulin at diagnosis are overweight. ${ }^{99}$ A combination of clinical features, pancreatic autoantibodies, insulin level and c-peptide (beyond the acute presentation) may be needed to establish a diagnosis. ${ }^{93}$ Assigning an accurate diagnosis as soon as possible will facilitate implementation of the most appropriate management plan.

\section{Management of type 2 diabetes mellitus}

Type 2 diabetes is one of the most challenging complications of obesity presenting in childhood. In addition to the potentially complex medical management that may be required, children with type 2 diabetes are at high risk of depression, ${ }^{100,101}$ 
which is associated with poor metabolic control. ${ }^{102}$ Health-related quality of life is noted to be reduced in children with type 2 diabetes, who have lower health-related quality of life than children with type 1 diabetes in all domains and have the greatest impairment in emotional functioning and school functioning. ${ }^{103}$ Therefore, management of type 2 diabetes in youth requires a team approach that ideally includes a physician, diabetes nurse educator, mental health specialist, and nutritionist. Collaboration with the child's school, including nursing and mental health specialists, provides additional support from staff who interact with the child daily. ${ }^{104}$

\section{Lifestyle modification}

Medical nutrition therapy is fundamental to the successful treatment of type 2 diabetes. As discussed previously for the management of obesity, a multidisciplinary approach is most likely to be successful. Using approaches that involve the whole family is also critical as adolescents with type 2 diabetes are likely to be from families who have type 2 diabetes and/or engage in high risk lifestyle behaviors. ${ }^{105}$ Both healthful dietary change and physical activity along with the appropriate psychosocial supports should be included in all management plans for children and adolescents with type 2 diabetes. ${ }^{92,95}$ Modest weight loss in overweight and obese adults ${ }^{106}$ and adolescents ${ }^{107}$ has been associated with reductions in insulin resistance. However, type 2 diabetes is a progressive disorder with ongoing loss of beta cell function over time such that only a small minority of adults are able to manage diabetes with lifestyle modification alone. ${ }^{95,108}$ While the rate of beta cell failure in children is unknown, some studies suggest that it may be even faster than in adults. ${ }^{109}$ A major question exists about whether early aggressive management of type 2 diabetes can slow the rate of beta cell failure and thereby improve long-term outcomes. ${ }^{110}$ How aggressive therapy should be implemented is also an area of current debate and inquiry. ${ }^{110}$

\section{Medical management}

The optimal regimen or algorithm for medical management for type 2 diabetes in children is not clear. However, current guidelines from the American Diabetes Association recommend targeting treatment to achieve glycemic control with an $\mathrm{HbA}_{1 \mathrm{c}}<7 \% .{ }^{92}$ Studies of clinical populations in the US and UK have shown that most pediatric patients with type 2 diabetes are managed initially with insulin or metformin, alone or in combination. ${ }^{111,112} \mathrm{~A}$ recent report by Liberman et al, which drew data on 6 to 18 year olds from a commercially-insured population in the US, demonstrated that while metformin was the most commonly prescribed therapy, other antidiabetic agents were also being prescribed including sulfonylureas, insulin sensitizing agents (thiazolidinediones) and alpha-glucosidase inhibitors. ${ }^{113}$ Table 3 summarizes the studies on medical management of type 2 diabetes in children described below.

\section{Metformin}

In the US, metformin is the only oral agent for treatment of type 2 diabetes that is approved for use in children (age 10 years and older). Metformin's primary action is to decrease hepatic glucose production and, secondarily, to increase insulin sensitivity in peripheral tissues. Jones et al conducted a double-blind, placebo-controlled study of metformin for management of type 2 diabetes in pediatric patients and demonstrated both safety and efficacy. ${ }^{114}$ In this study, 82 children between the ages of 10 and 16 years with type 2 diabetes were randomized to either $1000 \mathrm{mg}$ of metformin twice daily or placebo for up to 16 weeks. Subjects receiving metformin had significantly better glycemic control measured by both fasting plasma glucose and $\mathrm{HbA}_{1 \mathrm{c}}(7.5 \%$ vs $8.6 \%$, $P<0.001$ at the last visit) compared to placebo without negative effects on body weight or lipids and comparable adverse events. ${ }^{114}$

Metformin is generally well tolerated. However, gastrointestinal side effects including abdominal discomfort, nausea and diarrhea occur in up to $50 \%$ of patients taking metformin, but discontinuation is uncommon. ${ }^{115}$ These side effects tend to decrease over time and can be minimized by a slow increase in dose and taking the medication with food. A very rare but serious side effect is lactic acidosis. ${ }^{116}$ However, risk for lactic acidosis can be reduced by avoiding use of the medication in contraindicated circumstances, ${ }^{116}$ which include renal impairment, hepatic dysfunction, congestive heart failure (unstable, in hospitalized patients, and/or with abnormal renal function), ${ }^{92}$ metabolic acidosis, and dehydration. Patients must also be advised to stop metformin with acute illnesses that place the patient at risk of dehydration, prior to surgeries when the patient must fast, or when the patient is having a radiographic study requiring iodinated contrast. A typical starting dose for metformin is $500 \mathrm{mg}$ daily, which can be gradually increased weekly in $500 \mathrm{mg}$ increments as needed and tolerated to a dose of $1000 \mathrm{mg}$ twice daily, which is considered optimal. ${ }^{117}$ Metformin is available as a liquid (Riomet ${ }^{\circledR} 500 \mathrm{mg} / 5 \mathrm{~mL}$ ) for children, who are unable to swallow tablets, and in an extended release formulation. Metformin use is associated 


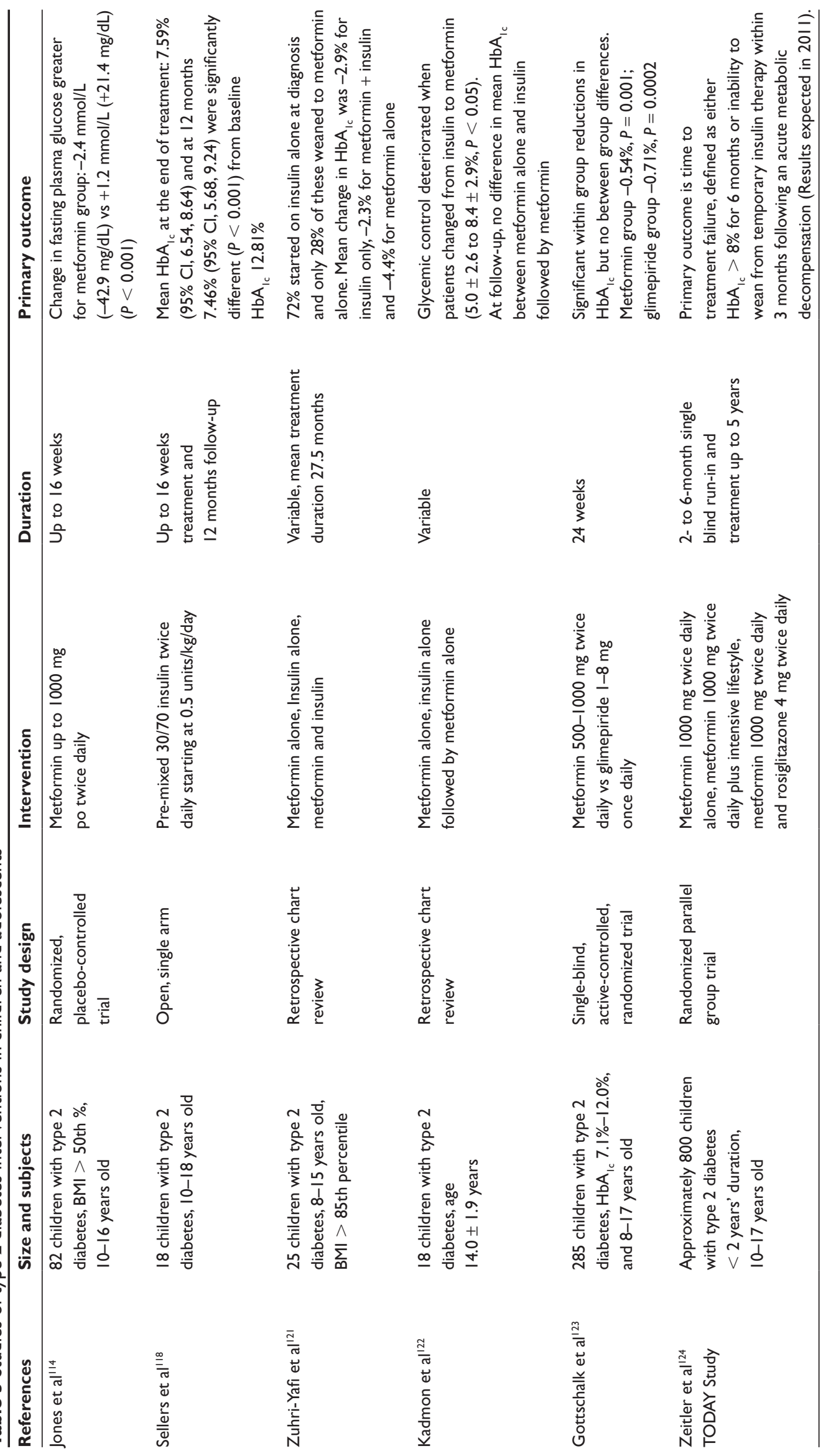


with decreased insulin resistance, limited weight gain and possible weight loss and, in some cases, modest improvement in lipid profiles. ${ }^{15,117}$ It can also improve ovulation in young women with polycystic ovarian syndrome. ${ }^{55}$ In addition to the low risk of hypoglycemia with metformin, these characteristics have made metformin the first-line oral medication for overweight adults with type 2 diabetes. ${ }^{115}$

\section{Insulin therapy}

Insulin is a frequently used therapy in type 2 diabetes management in children as it is one of the only two approved medical therapies. The major side effects associated with insulin therapy are hypoglycemia and weight gain. However, use of insulin is necessary at the time of diagnosis for children with severely uncontrolled diabetes or in addition to monotherapy with an oral agent (typically metformin) when target glycemic control is not achieved. Severely uncontrolled diabetes with evidence of catabolism is typically evidenced by an $\mathrm{HbA}_{1 \mathrm{c}}>10 \%$, fasting blood glucose $>250 \mathrm{mg} / \mathrm{dL}$, random blood glucose $>300 \mathrm{mg} / \mathrm{dL}$, ketonuria/ketoacidosis, or symptomatic diabetes with polyuria, polydipsia and weight loss. ${ }^{117}$ Use of short-term insulin therapy to reduce glucotoxicity may improve beta cell function. ${ }^{110}$ In a small study with 18 adolescents, Sellers et al demonstrated that improvements in $\mathrm{HbA}_{1 \mathrm{c}}$ following short-term (4 months) insulin therapy persisted up to 12 months without additional drug therapy. ${ }^{118}$

There are a number of insulin regimens available. They incorporate a combination of an intermediate-acting insulin (such as NPH) and/or a long-acting insulin (such as insulin detemir or insulin glargine) for basal coverage along with a short- or rapid-acting insulin (such as Regular, insulin aspart, insulin lispro, or insulin glulisine) to provide prandial glycemic coverage. Once the initial blood glucose levels have been stabilized, insulin can often be weaned as the dose of oral hypoglycemic medication is advanced. Whereas adolescents with type 1 diabetes may require 1 to $1.5 \mathrm{U} / \mathrm{kg} /$ day of insulin, ${ }^{119}$ those with type 2 diabetes may require even greater doses of insulin because of insulin resistance. Different algorithms for the introduction of insulin and advancement of insulin have been suggested. ${ }^{117,120}$ When added to metformin therapy, beginning with a long-acting insulin, such as insulin glargine, given at bedtime may minimize the risk of hypoglycemia. ${ }^{120}$

Few studies have specifically evaluated the relationship of insulin and metformin in the management of pediatric type 2 diabetes. ${ }^{121,122}$ Zuhri-Yafi et al performed a retrospective review of 25 children with type 2 diabetes ranging in age from 8 to 15 years at diagnosis. Insulin $(72 \%)$ or metformin
(28\%) were used as monotherapy at diagnosis depending on the severity of presentation. Only 5 of 18 patients started on insulin could be completely weaned to metformin, and 3 of these 5 then required reintroduction of insulin to maintain adequate glycemic control. Despite maximal dosing among the patients started on metformin monotherapy, 3 of 7 required the addition of another oral hypoglycemic (a sulfonylurea) by 6 months to maintain glycemic control. ${ }^{121}$ Kadmon et al conducted a retrospective review of 18 adolescents with an average age of $14.0 \pm 1.9$ years at diagnosis of whom 11 were initially treated with insulin and then transitioned to metformin, and 7 were treated with metformin alone. ${ }^{122}$ Glycemic control deteriorated when patients were transitioned from insulin to metformin with an increase in average $\mathrm{HbA}_{1 \mathrm{c}}$ from $5.0 \%$ to $8.4 \%$. This was similar to control achieved with those initially managed with metformin alone although those with better compliance achieved better $\mathrm{HbA}_{1 \mathrm{c}}$ results. Questionnaires completed prospectively by these patients indicated that those initially treated with insulin and transitioned to metformin may not view diabetes managed by pills alone to be as serious a disease as diabetes managed with insulin. These studies suggest that monotherapy with metformin may not be sufficient long-term therapy for youth with type 2 diabetes initially requiring insulin. However, these studies are small and retrospective. Larger, prospective studies are necessary to clarify whether these patterns apply more broadly to all youth with type 2 diabetes.

\section{Other antihyperglycemic therapies and combination therapy}

In adults with type 2 diabetes, after 3 years, only $50 \%$ are able to achieve target glycemic control with monotherapy. ${ }^{108}$ However, little is known about the efficacy and safety of other antihyperglycemic therapies as monotherapy or combination therapy in youth with type 2 diabetes. As metformin and insulin are currently the only approved therapies for use in children, metformin combined with insulin is frequently the first choice for combination therapy. ${ }^{120,121}$

Beyond metformin, antihyperglycemic therapies can be divided into categories based on their mechanism of action. These include insulin sensitizers (thiazolidinediones); insulin secretagogues (sulfonylureas, meglitinides, incretin mimetics, DPP-IV inhibitors); glucosidase inhibitors (acarbose, miglitol); and amylin receptor agonists (pramlintide). None of these medications have approval in the US for the treatment of type 2 diabetes in children. Descriptions of the dosing, contraindications, side effects and monitoring of these medications are outlined in Table 4. 


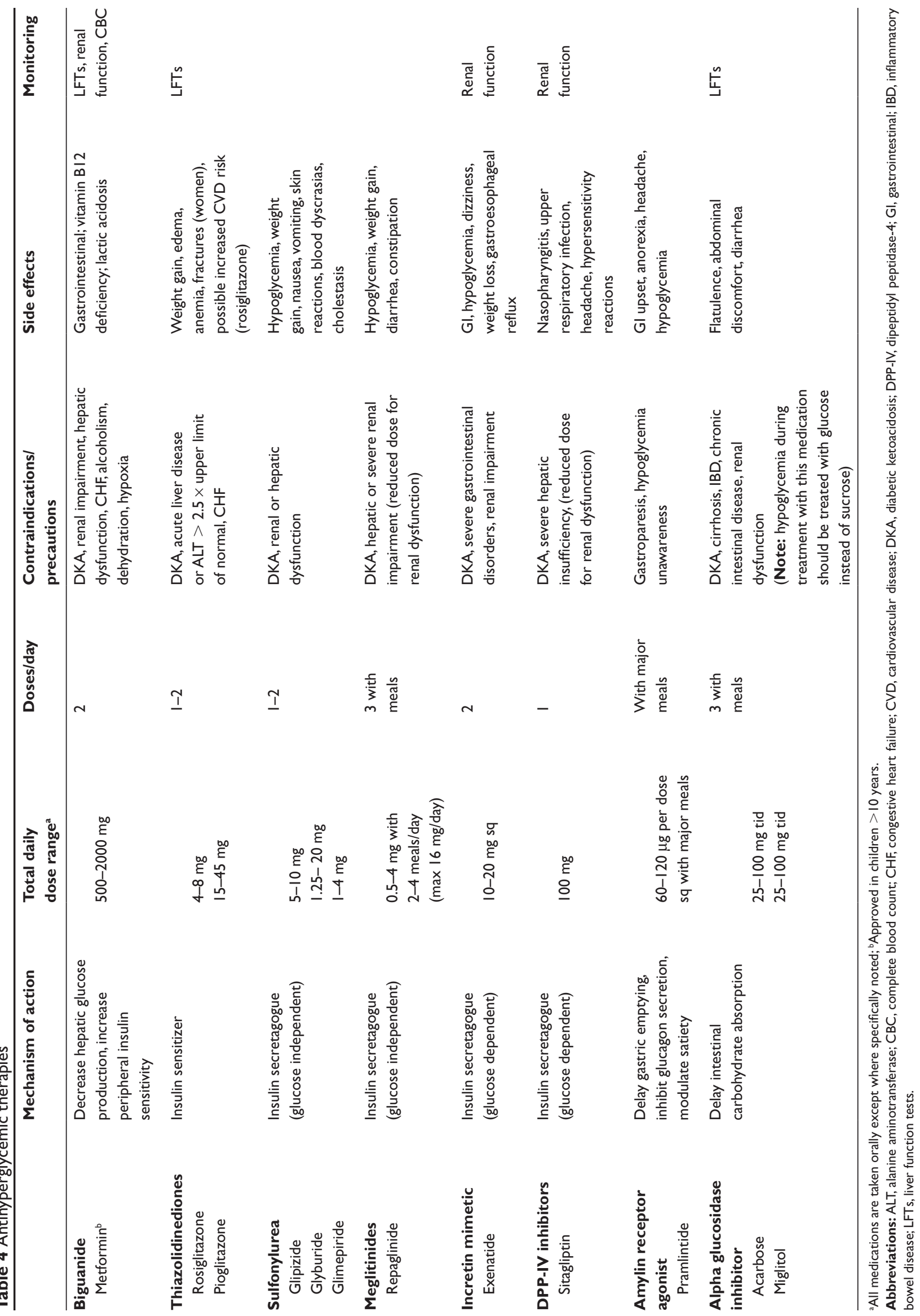


Despite the widespread use of metformin, few studies have actually been conducted in the pediatric population comparing metformin to other treatments for type 2 diabetes. Gottschalk et al compared metformin 500 to $1000 \mathrm{mg}$ twice daily to glimepiride 1 to $8 \mathrm{mg}$ once daily, a second-generation sulfonylurea, among 285 children with type 2 diabetes between the ages of 8 and 17 years. They found comparable reductions in $\mathrm{HbA}_{1 \mathrm{c}}$ after 24 weeks $(-0.7 \%$ with glimepiride vs $-0.85 \%$ with metformin, $P=0.542)$ but greater weight gain with the glimepiride $(1.97 \mathrm{~kg}$ vs $0.55 \mathrm{~kg}$, $P=0.005) .{ }^{123}$ Overall, the proportion experiencing adverse events and clinically relevant hypoglycemia were similar in the two groups. Hyperglycemia and upper abdominal pain occurred in a greater proportion of subjects treated with glimepiride whereas other gastrointestinal complaints and headache occurred in a greater proportion treated with metformin. ${ }^{123}$ In the TODAY (Treatment Options for Type 2 Diabetes in Adolescents and Youth) study, a large multicenter, randomized parallel group trial, metformin alone is being compared to metformin with an intensive lifestyle intervention and metformin with rosiglitazone (a thiazolidinedione). ${ }^{124}$ Subjects in this study are between 10 and 17 years of age with type 2 diabetes of at most 2 years' duration. The primary outcome is time to treatment failure, defined as either $\mathrm{HbA}_{1 \mathrm{c}}>8 \%$ for 6 months or inability to wean from temporary insulin therapy within 3 months following an acute metabolic decompensation. ${ }^{124}$ This study will inform the early management of type 2 diabetes in youth in terms of both the composition and intensity of therapy. Results of the study are expected in 2011.

\section{Bariatric surgery}

As discussed above, ${ }^{81}$ there is evidence to support the resolution of diabetes, ie, normalization of blood glucose levels in the absence of medications, in adolescents with type 2 diabetes who have undergone bariatric surgery. Adult studies suggest that the resolution rates are best with procedures that bypass portions of the small intestine. ${ }^{125}$ The American Diabetes Association recommends that bariatric surgery be considered in adults with a BMI $\geq 35 \mathrm{~kg} / \mathrm{m}^{2}$ and type 2 diabetes especially if the diabetes is difficult to control with lifestyle and pharmacologic therapy. ${ }^{92}$ The additional issues that must be taken into consideration for children and adolescents with type 2 diabetes are discussed above.

\section{Complications of diabetes}

Children and adolescents with type 2 diabetes are at risk for microvascular and macrovascular complications. ${ }^{126,127}$ Due to the added threat of adiposity, ${ }^{127,128}$ youth with type 2 diabetes may present with higher rates of complications earlier in the disease process than youth with type 1 diabetes. ${ }^{129-131}$ Therefore, more extensive screening is recommended at diagnosis. ${ }^{92}$ At diagnosis, screening should include a fasting lipid profile (once glycemic control has been achieved), urine microalbumin, and dilated eye examination. ${ }^{92}$ Subsequent eye examinations should be performed annually or less frequently following one or more normal examinations. Urine microalbumin should be performed annually. Two of three specimens collected in a 3- to 6-month period must be abnormal (30-299 $\mu \mathrm{g} / \mathrm{mg} \mathrm{Cr}$ ) before assigning a diagnosis of microalbuminuria. Lipids should be monitored every 2 years if normal and at least yearly if abnormal. Blood pressure should be checked at each visit. Guidelines for the management of dyslipidemia, ${ }^{132}$ hypertension, ${ }^{92}$ and albuminuria $^{92}$ in youth with type 2 diabetes are available. Clinical symptoms of autonomic neuropathy should be reviewed annually, ${ }^{92}$ and a yearly foot examination is also recommended although the benefit in this age group has not clearly been established. ${ }^{95}$

Smoking, alcohol consumption, and pregnancy in adolescent girls can be additionally problematic for youth with type 2 diabetes and should be routinely addressed in clinical encounters. Smoking may increase the risk for microalbuminuria ${ }^{133}$ and contribute to the risk of macrovascular disease. ${ }^{134}$ Youth with type 2 diabetes should also receive routine dental care, ${ }^{135}$ annual influenza vaccination and, based on newly revised vaccine recommendations, children with diabetes age $\geq 2$ years should receive a pneumococcal polysaccharide vaccination. ${ }^{92}$

\section{Conclusion}

In conclusion, obesity is an epidemic in childhood worldwide, and the rates of type 2 diabetes in youth are rising in association. Treatment options for obesity, insulin resistance, metabolic syndrome and type 2 diabetes in youth include a comprehensive lifestyle modification plan and careful consideration of medical and/or surgical interventions. However, the data supporting available treatments remain limited. The treatment of obesity and related metabolic abnormalities in children is an area of intense scientific interest, ripe for further investigation.

\section{Acknowledgments}

We would like to thank Stavroula Osganian, MD, ScD, MPH for her thoughtful review of the manuscript. 


\section{Disclosures}

Dr Rhodes receives salary support from an unrestricted, philanthropic grant from the New Balance Foundation to Dr David Ludwig at Children's Hospital Boston. Dr Rhodes was formerly the Chief Medical Officer for Pediatric Weight Management Centers, LLC's Great Moves! Program, which was privately owned and operated in collaboration with the physicians of Children's Hospital Boston. Dr Rhodes neither had nor has any equity or other economic interest in the business. Dr Fleischman discloses no conflicts of interest.

\section{References}

1. Olshansky SJ, Passaro DJ, Hershow RC, et al. A potential decline in life expectancy in the United States in the 21 st century. N Engl J Med. 2005;352(11):1138-1145.

2. World Health Organization. World Health Statistics 2009. URL: http:// www.who.int/whosis/whostat/EN_WHS09_Full.pdf Accessed 7/8/09.

3. Barlow SE. Expert committee recommendations regarding the prevention, assessment, and treatment of child and adolescent overweight and obesity: summary report. Pediatrics. 2007;120 Suppl 4:S164-S192.

4. 2000 CDC Growth Charts: United States. http://www.cdc.gov/ growthcharts/.Accessed July 8, 2009.

5. Cole TJ, Bellizzi MC, Flegal KM, Dietz WH. Establishing a standard definition for child overweight and obesity worldwide: international survey. BMJ. 2000;320(7244):1240-1243.

6. Ogden CL, Flegal KM, Carroll MD, Johnson CL. Prevalence and trends in overweight among US children and adolescents, 1999-2000. JAMA. 2002;288(14):1728-1732.

7. Ogden CL, Carroll MD, Flegal KM. High body mass index for age among US children and adolescents, 2003-2006. JAMA.2008;299(20): 2401-2405.

8. Cali AM, Caprio S. Obesity in children and adolescents. J Clin Endocrinol Metab. 2008;93(11 Suppl 1):S31-S36.

9. Must A, Jacques PF, Dallal GE, Bajema CJ, Dietz WH. Long-term morbidity and mortality of overweight adolescents. A follow-up of the Harvard Growth Study of 1922 to 1935. N Engl J Med. 1992;327(19): 1350-1355.

10. Freedman DS, Patel DA, Srinivasan SR, et al. The contribution of childhood obesity to adult carotid intima-media thickness: the Bogalusa Heart Study. Int J Obes (Lond). 2008;32(5):749-756.

11. Daniels SR, Greer FR. Lipid screening and cardiovascular health in childhood. Pediatrics. 2008;122(1):198-208.

12. The Fourth Report on the Diagnosis, Evaluation, and Treatment of High Blood Pressure in Children and Adolescents. NIH Publication No. 05-5267. May 2005.

13. Zimmet P, Alberti G, de Courten MP. New classification and criteria for diabetes: moving the goalposts closer. Med J Aust. 1998;168(12): 593-594.

14. Grundy SM, Cleeman JI, Merz CN, et al. A summary of implications of recent clinical trials for the National Cholesterol Education Program Adult Treatment Panel III guidelines. Arterioscler Thromb Vasc Biol. 2004;24(8):1329-1330.

15. Alberti KG, Zimmet P, Shaw J. Metabolic syndrome - a new worldwide definition. A Consensus Statement from the International Diabetes Federation. Diabet Med. 2006;23(5):469-480.

16. Grundy SM, Brewer HB Jr, Cleeman JI, Smith SC Jr, Lenfant C. Definition of metabolic syndrome: report of the National Heart, Lung, and Blood Institute/American Heart Association conference on scientific issues related to definition. Arterioscler Thromb Vasc Biol. 2004; 24(2):e13-e18

17. Zimmet P, Alberti G, Kaufman F, et al. The metabolic syndrome in children and adolescents. Lancet. 2007;369(9579):2059-2061.
18. de Ferranti SD, Gauvreau K, Ludwig DS, Newburger JW, Rifai N. Inflammation and changes in metabolic syndrome abnormalities in US adolescents: findings from the 1988-1994 and 1999-2000 National Health and Nutrition Examination Surveys. Clin Chem. 2006;52(7):1325-1330.

19. Cook S, Weitzman M, Auinger P, Nguyen M, Dietz WH. Prevalence of a metabolic syndrome phenotype in adolescents: findings from the third National Health and Nutrition Examination Survey, 1988-1994. Arch Pediatr Adolesc Med. 2003;157(8):821-827.

20. Weiss R, Dziura J, Burgert TS, et al. Obesity and the metabolic syndrome in children and adolescents. N Engl J Med. 2004;350(23): 2362-2374.

21. Cruz ML, Goran MI. The metabolic syndrome in children and adolescents. Curr Diab Rep. 2004;4(1):53-62.

22. Berenson GS, Srinivasan SR, Bao W, Newman WP 3rd, Tracy RE, Wattigney WA. Association between multiple cardiovascular risk factors and atherosclerosis in children and young adults. The Bogalusa Heart Study. N Engl J Med. 1998;338(23):1650-1656.

23. Goodman E, Daniels SR, Meigs JB, Dolan LM. Instability in the diagnosis of metabolic syndrome in adolescents. Circulation. 2007;115(17):2316-2322.

24. Wiegand S, Maikowski U, Blankenstein O, Biebermann H, Tarnow P, Gruters A. Type 2 diabetes and impaired glucose tolerance in European children and adolescents with obesity - a problem that is no longer restricted to minority groups. Eur J Endocrinol. 2004;151(2):199-206.

25. Kiess W, Bottner A, Raile K, et al. Type 2 diabetes mellitus in children and adolescents: a review from a European perspective. Horm Res. 2003;59 Suppl 1:77-84.

26. Urakami T, Kubota S, Nitadori Y, Harada K, Owada M, Kitagawa T. Annual incidence and clinical characteristics of type 2 diabetes in children as detected by urine glucose screening in the Tokyo metropolitan area. Diabetes Care. 2005;28(8):1876-1881.

27. Kitagawa T, Owada M, Urakami T, Yamauchi K. Increased incidence of non-insulin dependent diabetes mellitus among Japanese schoolchildren correlates with an increased intake of animal protein and fat. Clin Pediatr (Phila). 1998;37(2):111-115.

28. McGrath NM, Parker GN, Dawson P. Early presentation of type 2 diabetes mellitus in young New Zealand Maori. Diabetes Res Clin Pract. 1999;43(3):205-209.

29. Haines L, Wan KC, Lynn R, Barrett TG, Shield JP. Rising incidence of type 2 diabetes in children in the U.K. Diabetes Care. 2007;30(5): 1097-1101.

30. Lammi N, Taskinen O, Moltchanova E, et al. A high incidence of type 1 diabetes and an alarming increase in the incidence of type 2 diabetes among young adults in Finland between 1992 and 1996. Diabetologia. 2007;50(7):1393-1400.

31. Ehtisham S, Hattersley AT, Dunger DB, Barrett TG. First UK survey of paediatric type 2 diabetes and MODY. Arch Dis Child. 2004;89(6): 526-529.

32. Bell RA, Mayer-Davis EJ, Beyer JW, et al. Diabetes in non-Hispanic white youth: prevalence, incidence, and clinical characteristics: the SEARCH for Diabetes in Youth Study. Diabetes Care. 2009;32 Suppl 2: S102-S111.

33. Dabelea D, DeGroat J, Sorrelman C, et al. Diabetes in Navajo youth: prevalence, incidence, and clinical characteristics: the SEARCH for Diabetes in Youth Study. Diabetes Care. 2009;32 Suppl 2:S141-S147.

34. Lawrence JM, Mayer-Davis EJ, Reynolds K, et al. Diabetes in Hispanic American youth: prevalence, incidence, demographics, and clinical characteristics: the SEARCH for Diabetes in Youth Study. Diabetes Care. 2009;32 Suppl 2:S123-S132.

35. Liu LL, Yi JP, Beyer J, et al. Type 1 and Type 2 diabetes in Asian and Pacific Islander U.S. youth: the SEARCH for Diabetes in Youth Study. Diabetes Care. 2009;32 Suppl 2:S133-S140.

36. Mayer-Davis EJ, Beyer J, Bell RA, et al. Diabetes in African American youth: prevalence, incidence, and clinical characteristics: the SEARCH for Diabetes in Youth Study. Diabetes Care. 2009;32 Suppl 2: S112-S122. 
37. August GP, Caprio S, Fennoy I, et al. Prevention and treatment of pediatric obesity: an endocrine society clinical practice guideline based on expert opinion. J Clin Endocrinol Metab. 2008;93(12):4576-4599.

38. Oude Luttikhuis H, Baur L, Jansen H, et al. Interventions for treating obesity in children. Cochrane Database Syst Rev. 2009(1):CD001872.

39. Whitlock E, O'Connor E, Williams S, Beil T, Lutz K. Effectiveness of Weight Management Programs in Children and Adolescents. Evidence Report/Technology Assessment No. 170 (Prepared by Oregon Evidencebased Practice Center under Contract No. 290-02-0024.) AHRQ Publication 08-E014. Rockville MD: Agency for Healthcare Research and Quality. September 2008.

40. Collins CE, Warren J, Neve M, McCoy P, Stokes BJ. Measuring effectiveness of dietetic interventions in child obesity: a systematic review of randomized trials. Arch Pediatr Adolesc Med. 2006;160(9): 906-922.

41. Rhodes ET, Ludwig DS. Childhood obesity as a chronic disease: keeping the weight off. JAMA. 2007;298(14):1695-1696.

42. Ebbeling CB, Leidig MM, Sinclair KB, Hangen JP, Ludwig DS. A reduced-glycemic load diet in the treatment of adolescent obesity. Arch Pediatr Adolesc Med. 2003;157(8):773-779.

43. Saelens BE, Sallis JF, Wilfley DE, Patrick K, Cella JA, Buchta R. Behavioral weight control for overweight adolescents initiated in primary care. Obes Res. 2002;10(1):22-32.

44. www.cdc.gov/physicalactivity/everyone/guidelines/children.html Accessed 7/21/09.

45. Benson AC, Torode ME, Fiatarone Singh MA. Effects of resistance training on metabolic fitness in children and adolescents: a systematic review. Obes Rev. 2008;9(1):43-66.

46. Tuomilehto J, Lindstrom J, Eriksson JG, et al. Prevention of type 2 diabetes mellitus by changes in lifestyle among subjects with impaired glucose tolerance. $N$ Engl J Med. 2001;344(18):1343-1350.

47. Nassis GP, Papantakou K, Skenderi K, et al. Aerobic exercise training improves insulin sensitivity without changes in body weight, body fat, adiponectin, and inflammatory markers in overweight and obese girls. Metabolism. 2005;54(11):1472-1479.

48. Carrel AL, Clark RR, Peterson SE, Nemeth BA, Sullivan J, Allen DB. Improvement of fitness, body composition, and insulin sensitivity in overweight children in a school-based exercise program: a randomized, controlled study. Arch Pediatr Adolesc Med. 2005;159(10):963-968.

49. Bell LM, Watts K, Siafarikas A, et al. Exercise alone reduces insulin resistance in obese children independently of changes in body composition. J Clin Endocrinol Metab. 2007;92(11):4230-4235.

50. Barlow SE, Ohlemeyer CL. Parent reasons for nonreturn to a pediatric weight management program. Clin Pediatr (Phila). 2006;45:355-360.

51. Cote MP, Byczkowski T, Kotagal U, Kirk S, Zeller M, Daniels S. Service quality and attrition: An examination of a pediatric obesity program. Int J Qual Health Care. 2004;16(2):165-173.

52. McGovern L, Johnson JN, Paulo R, et al. Clinical review: treatment of pediatric obesity: a systematic review and meta-analysis of randomized trials. J Clin Endocrinol Metab. 2008;93(12):4600-4605.

53. Park MH, Kinra S, Ward KJ, White B, Viner RM. Metformin for obesity in children and adolescents: a systematic review. Diabetes Care. 2009;32(9):1743-1745.

54. Knowler WC, Barrett-Connor E, Fowler SE, et al. Reduction in the incidence of type 2 diabetes with lifestyle intervention or metformin. N Engl J Med. 2002;346(6):393-403.

55. Allen HF, Mazzoni C, Heptulla RA, et al. Randomized controlled trial evaluating response to metformin versus standard therapy in the treatment of adolescents with polycystic ovary syndrome. $J$ Pediatr Endocrinol Metab. 2005;18(8):761-768.

56. Roberts EA, Yap J. Nonalcoholic Fatty Liver Disease (NAFLD): Approach in the Adolescent Patient. Curr Treat Options Gastroenterol. 2006;9(5):423-431.

57. Freemark M, Bursey D. The effects of metformin on body mass index and glucose tolerance in obese adolescents with fasting hyperinsulinemia and a family history of type 2 diabetes. Pediatrics. 2001; 107(4):E55.
58. Kay JP, Alemzadeh R, Langley G, D'Angelo L, Smith P, Holshouser S. Beneficial effects of metformin in normoglycemic morbidly obese adolescents. Metabolism. 2001;50(12):1457-1461.

59. Srinivasan S, Ambler GR, Baur LA, et al. Randomized, controlled trial of metformin for obesity and insulin resistance in children and adolescents: improvement in body composition and fasting insulin. J Clin Endocrinol Metab. 2006;91(6):2074-2080.

60. Atabek ME, Pirgon O. Use of metformin in obese adolescents with hyperinsulinemia: a 6-month, randomized, double-blind, placebocontrolled clinical trial. J Pediatr Endocrinol Metab. 2008;21(4): 339-348.

61. Love-Osborne K, Sheeder J, Zeitler P. Addition of metformin to a lifestyle modification program in adolescents with insulin resistance. J Pediatr. 2008;152(6):817-822.

62. Yanovski JA, Sorg RA, Krakoff J, et al. A randomized-placebo controlled trial of the effects of metformin on body weight and body composition in children with insulin resistance (abstract). The Endocrine Society's 90th Annual Meeting. San Francisco, CA 2008.

63. Fu JF, Liang L, Zou CC, et al. Prevalence of the metabolic syndrome in Zhejiang Chinese obese children and adolescents and the effect of metformin combined with lifestyle intervention. Int J Obes (Lond). 2007;31(1):15-22.

64. Ibanez L, Valls C, Potau N, Marcos MV, de Zegher F. Sensitization to insulin in adolescent girls to normalize hirsutism, hyperandrogenism, oligomenorrhea, dyslipidemia, and hyperinsulinism after precocious pubarche. J Clin Endocrinol Metab. 2000;85(10):3526-3530.

65. Ibanez L, Lopez-Bermejo A, Diaz M, Marcos MV, de Zegher F. Metformin treatment for four years to reduce total and visceral fat in low birth weight girls with precocious pubarche. J Clin Endocrinol Metab. 2008;93(5):1841-1845.

66. Ibanez L, Ong K, Valls C, Marcos MV, Dunger DB, de Zegher F. Metformin treatment to prevent early puberty in girls with precocious pubarche. J Clin Endocrinol Metab. 2006;91(8):2888-2891.

67. Berkowitz RI, Wadden TA, Tershakovec AM, Cronquist JL. Behavior therapy and sibutramine for the treatment of adolescent obesity: a randomized controlled trial. JAMA. 2003;289(14):1805-1812.

68. Godoy-Matos A, Carraro L, Vieira A, et al. Treatment of obese adolescents with sibutramine: a randomized, double-blind, controlled study. $J$ Clin Endocrinol Metab. 2005;90(3):1460-1465.

69. Van Mil EG, Westerterp KR, Kester AD, Delemarre-van de Waal HA, Gerver WJ, Saris WH. The effect of sibutramine on energy expenditure and body composition in obese adolescents. J Clin Endocrinol Metab. 2007;92(4):1409-1414.

70. Berkowitz RI, Fujioka K, Daniels SR, et al. Effects of sibutramine treatment in obese adolescents: a randomized trial. Ann Intern Med. 2006;145(2):81-90.

71. Daniels SR, Long B, Crow S, et al. Cardiovascular effects of sibutramine in the treatment of obese adolescents: results of a randomized, double-blind, placebo-controlled study. Pediatrics. 2007;120(1): e147-e157.

72. McDuffie JR, Calis KA, Uwaifo GI, et al. Three-month tolerability of orlistat in adolescents with obesity-related comorbid conditions. Obes Res. 2002;10(7):642-650.

73. McDuffie JR, Calis KA, Uwaifo GI, et al. Efficacy of orlistat as an adjunct to behavioral treatment in overweight African American and Caucasian adolescents with obesity-related co-morbid conditions. J Pediatr Endocrinol Metab. 2004;17(3):307-319.

74. Norgren S, Danielsson P, Jurold R, Lotborn M, Marcus C. Orlistat treatment in obese prepubertal children: a pilot study. Acta Paediatr 2003;92(6):666-670.

75. Ozkan B, Bereket A, Turan S, Keskin S. Addition of orlistat to conventional treatment in adolescents with severe obesity. Eur J Pediatr. 2004;163(12):738-741.

76. Maahs D, de Serna DG, Kolotkin RL, et al. Randomized, double-blind, placebo-controlled trial of orlistat for weight loss in adolescents. Endocr Pract. 2006;12(1):18-28. 
77. Chanoine JP, Hampl S, Jensen C, Boldrin M, Hauptman J. Effect of orlistat on weight and body composition in obese adolescents: a randomized controlled trial. JAMA. 2005;293(23):2873-2883.

78. McDuffie JR, Calis KA, Booth SL, Uwaifo GI, Yanovski JA. Effects of orlistat on fat-soluble vitamins in obese adolescents. Pharmacotherapy. 2002;22(7):814-822.

79. Adams TD, Gress RE, Smith SC, et al. Long-term mortality after gastric bypass surgery. $N$ Engl J Med. 2007;357(8):753-761.

80. Treadwell JR, Sun F, Schoelles K. Systematic review and meta-analysis of bariatric surgery for pediatric obesity. Ann Surg. 2008;248(5): 763-776.

81. Inge TH, Miyano G, Bean J, et al. Reversal of type 2 diabetes mellitus and improvements in cardiovascular risk factors after surgical weight loss in adolescents. Pediatrics. 2009;123(1):214-222.

82. Zeller MH, Modi AC, Noll JG, Long JD, Inge TH. Psychosocial functioning improves following adolescent bariatric surgery. Obesity (Silver Spring). 2009;17(5):985-990.

83. Tsai WS, Inge TH, Burd RS. Bariatric surgery in adolescents: recent national trends in use and in-hospital outcome. Arch Pediatr Adolesc Med. 2007;161(3):217-221.

84. Varela JE, Hinojosa MW, Nguyen NT. Perioperative outcomes of bariatric surgery in adolescents compared with adults at academic medical centers. Surg Obes Relat Dis. 2007;3(5):537-540; discussion 541-542.

85. Puzziferri N, Nakonezny PA, Livingston EH, Carmody TJ, Provost DA, Rush AJ. Variations of weight loss following gastric bypass and gastric band. Ann Surg. 2008;248(2):233-242.

86. Yitzhak A, Mizrahi S, Avinoach E. Laparoscopic gastric banding in adolescents. Obes Surg. 2006;16(10):1318-1322.

87. Horgan S, Holterman MJ, Jacobsen GR, et al. Laparoscopic adjustable gastric banding for the treatment of adolescent morbid obesity in the United States: a safe alternative to gastric bypass. J Pediatr Surg. 2005;40(1):86-90; discussion 90-91.

88. Gordon CM, DePeter KC, Feldman HA, Grace E, Emans SJ. Prevalence of vitamin D deficiency among healthy adolescents. Arch Pediatr Adolesc Med. 2004;158(6):531-537.

89. Harkness LS, Cromer BA. Vitamin D deficiency in adolescent females. J Adolesc Health. 2005;37(1):75.

90. Alvarez-Leite JI. Nutrient deficiencies secondary to bariatric surgery. Curr Opin Clin Nutr Metab Care. 2004;7(5):569-575.

91. Pratt JS, Lenders CM, Dionne EA, et al. Best practice updates for pediatric/adolescent weight loss surgery. Obesity (Silver Spring). 2009; 17(5):901-910.

92. American Diabetes Association Standards of medical care in diabetes - 2009. Diabetes Care. 2009;32 Suppl 1:S13-S61.

93. Rosenbloom AL, Silverstein JH, Amemiya S, Zeitler P, Klingensmith GJ. ISPAD Clinical Practice Consensus Guideline 2006-2007. Type 2 diabetes mellitus in the child and adolescent. Pediatr Diabetes. 2008; 9(5):512-526.

94. International Expert Committee report on the role of the $\mathrm{A} 1 \mathrm{C}$ assay in the diagnosis of diabetes. Diabetes Care. 2009;32(7):1327-1334.

95. Type 2 diabetes in children and adolescents. American Diabetes Association. Diabetes Care. 2000;23(3):381-389.

96. Jones KL. Role of obesity in complicating and confusing the diagnosis and treatment of diabetes in children. Pediatrics. 2008;121(2):361-368.

97. Gilliam LK, Brooks-Worrell BM, Palmer JP, Greenbaum CJ, Pihoker C. Autoimmunity and clinical course in children with type 1 , type 2, and type 1.5 diabetes. J Autoimmun. 2005;25(3):244-250.

98. Hathout EH, Thomas W, El-Shahawy M, Nahab F, Mace JW. Diabetic autoimmune markers in children and adolescents with type 2 diabetes. Pediatrics. 2001;107(6):E102.

99. Libman IM, Pietropaolo M, Arslanian SA, LaPorte RE, Becker DJ. Changing prevalence of overweight children and adolescents at onset of insulin-treated diabetes. Diabetes Care. 2003;26(10):2871-2875.

100. Levitt Katz LE, Swami S, Abraham M, et al. Neuropsychiatric disorders at the presentation of type 2 diabetes mellitus in children. Pediatr Diabetes. 2005;6(2):84-89.
101. Stewart SM, Rao U, White P. Depression and diabetes in children and adolescents. Curr Opin Pediatr. 2005;17(5):626-631.

102. Helgeson VS, Siminerio L, Escobar O, Becker D. Predictors of metabolic control among adolescents with diabetes: a 4-year longitudinal study. J Pediatr Psychol. 2009;34(3):254-270.

103. Naughton MJ, Ruggiero AM, Lawrence JM, et al. Health-related quality of life of children and adolescents with type 1 or type 2 diabetes mellitus: SEARCH for Diabetes in Youth Study. Arch Pediatr Adolesc Med. 2008;162(7):649-657.

104. American Diabetes Association. Diabetes care in the school and day care setting. Diabetes Care. 2009;32 Suppl 1:S68-S72.

105. Pinhas-Hamiel O, Standiford D, Hamiel D, Dolan LM, Cohen R, Zeitler PS. The type 2 family: a setting for development and treatment of adolescent type 2 diabetes mellitus. Arch Pediatr Adolesc Med. 1999;153(10):1063-1067.

106. Wing RR, Koeske R, Epstein LH, Nowalk MP, Gooding W, Becker D. Long-term effects of modest weight loss in type II diabetic patients. Arch Intern Med. 1987;147(10):1749-1753.

107. Savoye M, Shaw M, Dziura J, et al. Effects of a weight management program on body composition and metabolic parameters in overweight children: a randomized controlled trial. JAMA. 2007;297(24): 2697-2704

108. Turner RC, Cull CA, Frighi V, Holman RR. Glycemic control with diet, sulfonylurea, metformin, or insulin in patients with type 2 diabetes mellitus: progressive requirement for multiple therapies (UKPDS 49). UK Prospective Diabetes Study (UKPDS) Group. JAMA.1999; 281(21):2005-2012.

109. Gungor N, Arslanian S. Progressive beta cell failure in type 2 diabetes mellitus of youth. J Pediatr. 2004;144(5):656-659

110. Standl E. The importance of beta-cell management in type 2 diabetes. Int J Clin Pract Suppl. 2007(153):10-19.

111. Shield JP, Lynn R, Wan KC, Haines L, Barrett TG. Management and 1 year outcome for UK children with type 2 diabetes. Arch Dis Child. 2009;94(3):206-209.

112. Rapaport R, Silverstein JH, Garzarella L, Rosenbloom AL. Type 1 and type 2 diabetes mellitus in childhood in the United States: practice patterns by pediatric endocrinologists. J Pediatr Endocrinol Metab. 2004;17(6):871-877.

113. Liberman JN, Berger JE, Lewis M. Prevalence of antihypertensive, antidiabetic, and dyslipidemic prescription medication use among children and adolescents. Arch Pediatr Adolesc Med. 2009;163(4): 357-364

114. Jones KL, Arslanian S, Peterokova VA, Park JS, Tomlinson MJ. Effect of metformin in pediatric patients with type 2 diabetes: a randomized controlled trial. Diabetes Care. 2002;25(1):89-94.

115. Inzucchi SE. Oral antihyperglycemic therapy for type 2 diabetes: scientific review. JAMA. 2002;287(3):360-372.

116. Misbin RI. The phantom of lactic acidosis due to metformin in patients with diabetes. Diabetes Care. 2004;27(7):1791-1793

117. Nathan DM, Buse JB, Davidson MB, et al. Medical management of hyperglycemia in type 2 diabetes: a consensus algorithm for the initiation and adjustment of therapy: a consensus statement of the American Diabetes Association and the European Association for the Study of Diabetes. Diabetes Care. 2009;32(1): 193-203.

118. Sellers EA, Dean HJ. Short-term insulin therapy in adolescents with type 2 diabetes mellitus. J Pediatr Endocrinol Metab. 2004;17(11): 1561-1564.

119. Kerouz N, el-Hayek R, Langhough R, MacDonald MJ. Insulin doses in children using conventional therapy for insulin dependent diabetes. Diabetes Res Clin Pract. 1995;29(2):113-120.

120. Svoren B, Wolfsdorf JI. Management of Diabetes Mellitus in Children and Adolescents. International Diabetes Monitor. 2006; 18(5):9-18.

121. Zuhri-Yafi MI, Brosnan PG, Hardin DS. Treatment of type 2 diabetes mellitus in children and adolescents. J Pediatr Endocrinol Metab. 2002;15 Suppl 1:541-546. 
122. Kadmon PM, Gruppuso PA. Glycemic control with metformin or insulin therapy in adolescents with type 2 diabetes mellitus. J Pediatr Endocrinol Metab. 2004;17(9):1185-1193.

123. Gottschalk M, Danne T, Vlajnic A, Cara JF. Glimepiride versus metformin as monotherapy in pediatric patients with type 2 diabetes: a randomized, single-blind comparative study. Diabetes Care. 2007;30(4):790-794

124. Zeitler P, Epstein L, Grey M, et al. Treatment options for type 2 diabetes in adolescents and youth: a study of the comparative efficacy of metformin alone or in combination with rosiglitazone or lifestyle intervention in adolescents with type 2 diabetes. Pediatr Diabetes. 2007;8(2):74-87.

125. Buchwald H, Estok R, Fahrbach K, et al. Weight and type 2 diabetes after bariatric surgery: systematic review and meta-analysis. $\mathrm{Am} \mathrm{J}$ Med. 2009;122(3):248-256 e5.

126. Pinhas-Hamiel O, Zeitler P. Acute and chronic complications of type 2 diabetes mellitus in children and adolescents. Lancet. 2007; 369(9575):1823-1831.

127. West NA, Hamman RF, Mayer-Davis EJ, et al. Cardiovascular risk factors among youth with and without type 2 diabetes: differences and possible mechanisms. Diabetes Care. 2009;32(1):175-180.

128. Ebbeling C, Pawlak D, Ludwig D. Childhood obesity: public-health crisis, common sense cure. Lancet. 2002;360(9331):473.
129. Eppens MC, Craig ME, Cusumano J, et al. Prevalence of diabetes complications in adolescents with type 2 compared with type 1 diabetes. Diabetes Care. 2006;29(6):1300-1306.

130. Maahs DM, Snively BM, Bell RA, et al. Higher prevalence of elevated albumin excretion in youth with type 2 than type 1 diabetes: the SEARCH for Diabetes in Youth study. Diabetes Care. 2007;30(10): 2593-2598.

131. Petitti DB, Imperatore G, Palla SL, et al. Serum lipids and glucose control: the SEARCH for Diabetes in Youth study. Arch Pediatr Adolesc Med. 2007;161(2):159-165.

132. American Diabetes Association. Management of dyslipidemia in children and adolescents with diabetes. Diabetes Care. 2003;26(7): 2194-2197.

133. Sinha RN, PatrickAW, Richardson L, Wallymahmed M, MacFarlane IA. A six-year follow-up study of smoking habits and microvascular complications in young adults with type 1 diabetes. Postgrad Med J. 1997;73(859):293-294.

134. McGill HC Jr, McMahan CA, Zieske AW, Malcom GT, Tracy RE, Strong JP. Effects of nonlipid risk factors on atherosclerosis in youth with a favorable lipoprotein profile. Circulation. 2001;103(11): 1546-1550.

135. Kidambi S, Patel SB. Diabetes mellitus: considerations for dentistry. J Am Dent Assoc. 2008;139 Suppl:8S-18S.

\section{Publish your work in this journal}

Diabetes, Metabolic Syndrome and Obesity: Targets and Therapy is an international, peer-reviewed open-access journal committed to the rapid publication of the latest laboratory and clinical findings in the fields of diabetes, metabolic syndrome and obesity research. Original research, review, case reports, hypothesis formation, expert opinion and commentaries are all considered for publication. The manuscript management system is completely online and includes a very quick and fair peer-review system, which is all easy to use. Visit http://www.dovepress.com/testimonials.php to read real quotes from published authors. 